\title{
Influence of dynamic properties on scaffoldings safety
}

\author{
Ewa Błazik-Borowa' ${ }^{1}$ ( ) Jarosław Bęc ${ }^{1}[0$
}

Received: 13 February 2021 / Revised: 12 August 2021 / Accepted: 19 August 2021 / Published online: 1 September 2021

(c) The Author(s) 2021

\begin{abstract}
Scaffoldings are used for works at height and in places that are hard to reach, which makes such works dangerous to employees and accidents occur frequently. Loads generated by scaffolding users cannot be avoided. Moving workers excite low-frequency $(1-2 \mathrm{~Hz})$ vibrations and scaffoldings as slender structures are prone to such dynamic action. The method for determining the probability of vibrations excitation is presented here. The quantity representing this probability is called the predictor of occurrence of a dangerous situation due to vibrations induced by a walking employee. The predictor of resonance with $i$ th natural frequency requires an analysis of the scaffolding dynamic behavior. The frequencies and the natural mode shapes of vibrations were determined. Numerical dynamic simulations of the worker's movement on the penultimate decks of two scaffoldings were carried out, as well. Predictor analysis was made for single frequencies and combinations of frequency pairs. The predictor values calculated for the first frequency or combinations with it are the highest ones, however the probability of resonance is not only affected by the first frequency. To improve safety, the natural frequencies should be increased. For longitudinal vibrations, this can be done by adding more bracing or reducing lengths of anchors. Increasing the number of anchors gives good results in both directions. During scaffolding design of both typical and atypical constructions, one must determine the natural frequencies and then, if the first natural frequency is less than $4.0 \mathrm{~Hz}$, perform a dynamic scaffolding analysis.
\end{abstract}

Keywords Scaffolding $\cdot$ Human excited vibrations $\cdot$ Dynamic analysis $\cdot$ Accident predictor

\section{Introduction}

The number of accidents in the construction industry in 2016 in Europe was 371,732 [1] with 14,724,700 persons employed [2]. According to works [3, 4], accidents related to the use of scaffoldings make up about half of all accidents in civil engineering. The number of publications on occupational safety in this branch is constantly increasing. The paper [5] stated that by the end of 2017, 463 articles in English on this topic had been published and indexed in the Scopus database. However, before 1990, there were ten such works and only in 2017, there were 81 . Cited figures

Jarosław Bęc

j.bec@pollub.pl

Ewa Błazik-Borowa

e.blazik@pollub.pl

1 Faculty of Civil Engineering and Architecture, Lublin University of Technology, Nadbystrzycka 40, 20-618 Lublin, Poland confirm that work safety in the construction industry is a still important issue.

In 2016-2018, the PBS3/A2/19/2015 project "Modeling of risk assessment of construction disasters, accidents, and dangerous incidents at workplaces using scaffoldings" with the acronym ORKWIZ was implemented. The aim of this project was to develop a method for assessment of the risk of hazardous events on a scaffolding, which would consider five group of factors: legal, social, and economic conditions of surroundings, environmental conditions during work, technical conditions, organizational conditions, and human factors. As part of the ORKWIZ project, 120 scaffoldings and workers using them were tested throughout Poland. As part of these tests, the following work was performed during one working week [6-12]: scaffoldings inventory, damage level inventory, live loads inventory, wind action measurements, scaffoldings free vibrations measurements, measurements of scaffolding vibrations excited by the construction machinery, measurements of forces in standards, ground load capacity tests, anchor load capacity tests, measurements of air temperature and pressure, 
noise intensity level measurements, lighting measurements, surveys regarding general information on scaffolding and scaffolding users, analysis of compliance with health and safety regulations, analysis of construction site organization, surveys of scaffolding users, measurements of users' energy effort and changes in other physiological parameters during scaffolding works. Then, each of the five groups of factors was described by a model in which subsequent factors were included. Predictors of individual factors were determined based on the developed model. The predictor values describe the probability of potentially accidental situations on or in the vicinity of scaffolding and they are ranging from 0.0 to 1.0 . The value 0.0 means the scaffolding is safe and 1.0 refers to the scaffolding on which a dangerous situation will certainly occur due to reasons resulting from a given group of factors. Based on the predictors of the groups of factors, the final rating of the scaffolding is determined due to the requirement of ensuring safety to the employees. The model, named ORKWIZ after the project acronym, was fully presented at a dedicated conference in several types of research [13]. Due to the complexity of the model, it is not possible to present it in one publication. Model elements have already been described, for example, in $[9,11,14-20]$ and the work is underway on articles that will present further elements of the ORKWIZ model. Here in this paper, we present the method for determining the probability of vibrations excitation during the worker's passage, which has been classified into the group of technical factors.

\section{Research background}

As stated in the introduction, the occurrence of worker's accidents in construction is much more likely than in other industries. Therefore, much research is being carried out to develop tools to improve this situation. The number of literature items on this issue is constantly increasing and several researchers have already undertaken a thorough review of literature in this field. This includes studies such as [5, 21-26]. The mentioned works discuss papers that analyze the causes of accidents, risk assessment models, accident models, risk management methods and level of acceptable risk. As in this paper, only one element of the ORKWIZ model which estimates the probability of a potentially accidental situation is considered, this part of the paper presents only those works that deal with the quantitative assessment of the risk of an accident at a construction site.

In early 2011, New Zealand experienced the earthquake that led to rebuilding of the Canterbury region. Construction investments were conducted in 2011-2015. Accident research on these construction sites allowed [25] to analyze the relationship between the amount of accident claims and the number of companies and their size, which was measured by the sum of remuneration. They developed a model that predicts the size of accident claims related to work in construction based on the change in the number of active construction companies and depending on the total earnings of employees in the companies. This model evaluates the effects of accidents in macroscale but does not precisely analyze the causes. However, accident research required paying attention to this aspect as well. A quarter of the number of observed accidents during the reconstruction of the region were falls from heights, which shows that in research on accident rates, work at heights should be treated with special care.

An important group of safety assessment models is the group based on the assumption that the occupational safety and health risk assessment (OSH-R) is the product of the accident consequences (severity) and its probability. Exactly in such a form, this formula was given in [27], but other researchers [28] had already introduced exposure time to this formula, i.e. OSH-R as the product of severity, exposure and probability. This method of OSH-R calculating is used in many models, e.g., it was implemented into the safety equilibrium model by Hallowell and Gambatese [29] and in the Occupational Safety and Health Potential Risk Model (OSH-PRM) developed by Sousa et al. [30]. In the OSHPRM model, OSH-R is assessed using accident costs. The expected costs of accidents on a construction site are calculated as the sum of the costs of accidents that may occur for each type of construction work. On the other hand, the costs of accidents for one activity are calculated as the product of the number of employees performing this activity, the time of their exposure to the possibility of an accident, the accident exposure parameter for a given activity, costs of a single accident and the risk of an accident. The accident exposure parameter for a given activity is based on expert judgment, and the accident risk is calculated based on statistical analyzes of the number of accidents at construction sites during a year. The above-described method of calculating OSH-R requires determining the probability of an accident. The following methods are most often used for this purpose:

- Delphi method or others expert methods [31, 32],

- Fuzzy method [32, 33],

- AHP method [34, 35],

- AHP-fuzzy method [36, 37].

The ORKWIZ model is dedicated to situations related to the functioning of scaffolding at construction sites. It does not assess the causes and results of accidents but estimates a set of factors describing a given scaffolding in terms of work safety on the scaffolding and in its surroundings. The result of tests performed with the use of the ORKWIZ model shows the state of individual groups of factors and thus indicates how much safety can be improved and what should be 
improved to increase safety. In addition, the ORKWIZ model can also be a useful tool for insurance companies which, based on tests made for scaffolding used by companies, can assess the insurance risk of a given construction company. The scaffolding score, which is the predictor of an accident, describes the probability of an accident in activities at the scaffolding. On the other hand, the method of determining the predictor, resulting from the vibration sub-factor, can be used in the calculation of the risk associated with construction works at workplaces that are exposed to vibrations.

Scaffoldings are used for works at height and in places that are hard to reach. The characteristics of the works at scaffoldings makes them dangerous to employees. Scaffoldings should provide easy access to the workplace and ensure employee safety. Unfortunately, as it was written earlier, accidents associated with work at scaffoldings occur frequently. These are mainly: workers falling from scaffoldings, falls on scaffoldings, the impact of tools falling from scaffoldings and all kinds of effects of scaffoldings failures. Detailed analyzes of direct causes of accidents were shown in $[3-5,23,38-42]$.

The authors of these works mention, among others, such direct reasons for the occurrence of potentially accidental situations, as poor technical condition of scaffolding structural elements, poor technical condition of the safety devices or their absence, improper scaffolding shape, improper management, non-compliance with health and safety regulations, lack or improper use of personal protective equipment, electric shocks, poor psycho-physical condition of employees. The causes of accidents at the workplace, not only related to scaffoldings, but also according to [43] were divided into three groups: technical, human and organizational. This division is the basis for the analysis of accidents at work in Europe. In the research of Hamdan and Awang [40], the causes of accidents on scaffoldings have been divided into four groups, three mentioned above, and an additional group of environmental causes.

In works [3, 39], the authors made an approach to the problem of safety on scaffoldings in a different way. Here, the exploitation of scaffoldings was divided into five stages: preparation of scaffolding design documentation, selection of the set of elements to be used for scaffolding assembly, erection of scaffolding, operational stage of scaffolding, disassembly of scaffolding.

In [3], one more initial stage of scaffolding operation was added, namely: scaffolding preparation for production and placing on the market. It was then shown that an accident can be the result of errors at any of these stages. Stages have been associated with actions that affect the condition of a scaffolding, e.g., errors made at the stage of the system scaffolding formation and resulting from the legal situation, may have consequences in the form of poor technical condition of the scaffolding during its use. This means that the system is unstable, workers get tired very quickly and this is the reason for their lack of concentration, which can end up e.g. in falling from a height. This analysis and research results, also presented in the works of other authors (for example $[4,15,23,40])$, show that the following groups of factors influence the safety of work at scaffoldings:

- Legal, social, and economic factors describing the general socio-economic situation in a country, the state of legal regulations regarding the functioning of scaffoldings and the state of safety culture (value of construction products, the potential of construction companies, employment structures in the construction industry, work safety),

- Environmental factors which contain parameters of the working environment (air temperature, relative humidity, atmospheric pressure, wind speed and direction, sound intensity, high-frequency mechanical vibrations, lighting intensity, dustiness),

- Technical factors describing technical condition of a scaffolding, which include the load-bearing capacity of a structure (taking into account the state of foundations, random nature of material properties, damage to structural elements, geometric imperfections, anchoring conditions, load level of the structure), decks load-bearing capacity and susceptibility to vibrations, during the passage of workers,

- Organizational factors including selected parameters of work organization (supervision, coordination of works, organization of the workplace, human resources management, supply of working tools, elements storage) and compliance with health and safety procedures (health and safety trainings, medical examinations, attitude to compliance with health and safety regulations, assembly workers qualifications, documentation of assembly approval, scaffolding documentation, individual protection equipment), technical conditions of workers safety elements (handrails, toeboards, vertical circulation paths),

- Human factors describing the psycho-physical state and functioning of the employee in the work process as well as selected behavioral factors (health condition, energy effort, stress level, degree of coherence, locus of control, the hierarchy of values, risk perception).

This division of factors was first proposed in [3]. It differs from the classifications cited in other publications because legal-socio-economic factors were added, and technical factors included only the ones which are associated with the behavior of the structure under the influence of loads. However, those elements that are associated with ensuring security, i.e. the state of the handrails, have been moved to organizational factors. Additionally, in [44], two concepts 
are distinguished: factors that describe the conditions in which the scaffolding operates, and the causes that lead to dangerous situations that can develop into an accident. It should be mentioned here that according to Bird's accident triangle [45], there are 600 potentially accidental situations per one accident.

As mentioned in the introduction, the ORKWIZ model includes methods for determining predictors for five factors. The methods were developed based on authors' own research and research available in the literature. It is a model based on interdisciplinary research, including physics, mechanics, ergonomics, medicine, sociology, psychology, and construction. Unfortunately, this means that it is not possible to describe fully the methods of calculating the probability of dangerous situations, i.e. predictors for individual groups of factors, in a single paper. This article is devoted to the method of estimating the probability of an accident occurrence due to scaffolding vibrations caused by a worker walking over the structure. Research confirming that the instability of workplaces is an important factor influencing safety has been presented, inter-alia, in the works [46, 47]. However, there were no previous analyzes on methods of scaffolding assessment in terms of structure dynamic parameters affecting safety of workers. The effect of synchronization of the scaffolding vibrations and the excitation caused by human walking, has a negative impact on the safety of workers, both due to the possibility of failure of the structure and due to the fatigue of workers, which in turn can lead to many errors resulting in an accident.

\section{Research methodology}

\subsection{Human walking parameters}

Scaffolding loads generated by their users cannot be avoided. Workers on scaffolding not only work but must also get to the workplace. Moving on the structure, the low-frequency vibrations of $1.0-2.0 \mathrm{~Hz}$ are excited. In the case of slender structures with low natural frequencies, including scaffoldings [20,48], this type of excitation is a significant dynamic load, causing human discomfort and an increase in stress in structural elements $[14,49]$. This was the reason for considering the probability of vibrations excitation during the movement of employees in the assessment of scaffoldings in terms of safety.

Tests of structural loads caused by moving people have already been conducted for several decades. A significant number of investigations on this problem such as [50-53] were published in the 70s of the last century. Interest in this issue arises because the buildings which, for economic or aesthetic reasons, have low frequencies of natural vibrations, are being erected and these objects have a function related only to the presence of people. Such constructions are footbridges, stairs, stands of sports facilities and entertainment halls, as well as scaffoldings. The results of tests on the excitation of vibrations by moving the person into three forms walking, running, and jumping up were collected by Bachmann and Colleagues [54] and Racic et al. [55].

Figure 1 shows diagrams of the components of forces during two full steps and the fragment of the third one. The drawing was prepared following the update of the research results from the previously mentioned studies, which were presented in [56, 57]. As can be seen in this figure, during the human movement, besides the vertical component, a moving person causes also horizontal components along the direction of motion and in the perpendicular direction. In addition, the higher the speed of movement, the ratio of vertical force and human weight grows. According to the study of Wheeler [58], it follows that during normal walking, the movement speed varies from 1.1 to $1.5 \mathrm{~m} / \mathrm{s}$ and the step length $l_{\text {step }}$ is from 0.6 to $0.75 \mathrm{~m}$, respectively. The
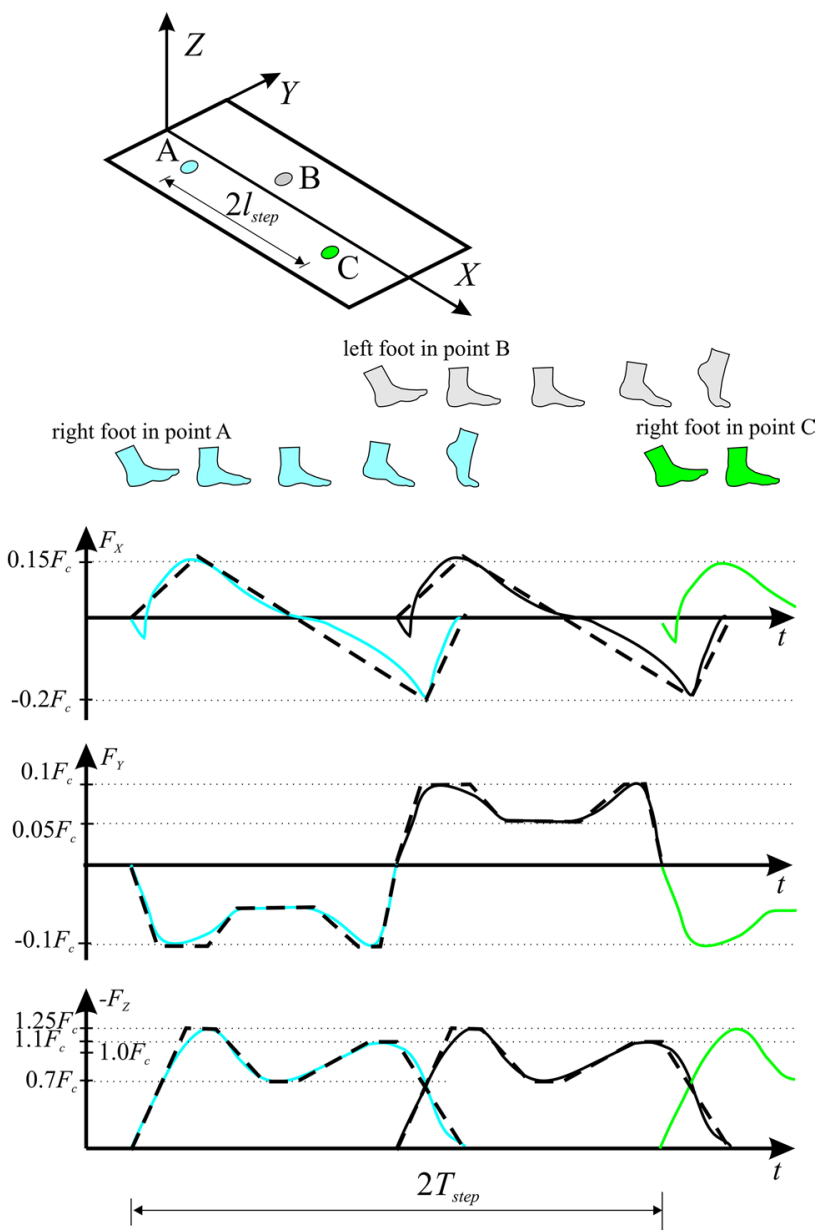

Fig. 1 Graphs of forces during normal walking of one person: continuous line-experimental results [54-57], dashed line-own loads model 
frequency of footsteps, which is also the frequency of excitation vibrations during the movement, depends on these two parameters.

All the worker's movement parameters listed, such as walking speed, step length and step frequency, depend on the worker's weight, height, and physical build. The diagrams in Fig. 1 show the most likely course of load during the movement. Nevertheless, the frequency distribution forced by employees is random. Based on investigations results of $[50,51,55,56]$ the following normal distributions of the vibration frequency probability density functions which can be caused by workers moving on the scaffolding, have been assumed:

- Vibrations excitation along the scaffolding decks

$$
p_{\mathrm{I}}(\lambda)=\frac{1}{0.173 \mathrm{~Hz} \sqrt{2 \pi}} \mathrm{e}^{-\frac{(\lambda-1.99 \mathrm{~Hz})^{2}}{2 \cdot(0.173 \mathrm{~Hz})^{2}}} .
$$

- Vibrations excitation in the direction perpendicular to scaffolding plane

$$
p_{\mathrm{II}}(\lambda)=\frac{1}{0.17 \mathrm{~Hz} \sqrt{2 \pi}} \mathrm{e}^{-\frac{(\lambda-0.91 \mathrm{~Hz})^{2}}{2 \cdot(0.17 \mathrm{~Hz})^{2}}} .
$$

Diagrams of normal distributions, described with Eqs. (1) and (2), are shown in Fig. 2.

\subsection{Probability of vibrations excitation during the worker's movement}

The most dangerous scaffolding vibration excitations are the ones with the frequency close to the frequency of natural vibrations. The scaffolding vibrational safety assessment consist in determination of the probability of resonance

\section{a}

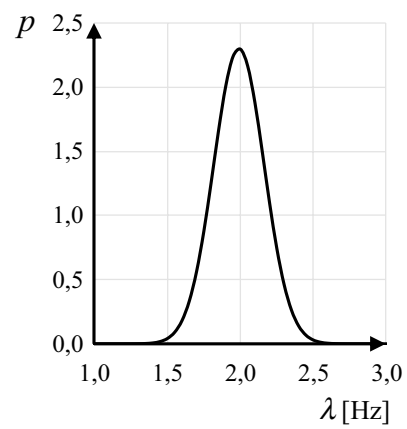

b

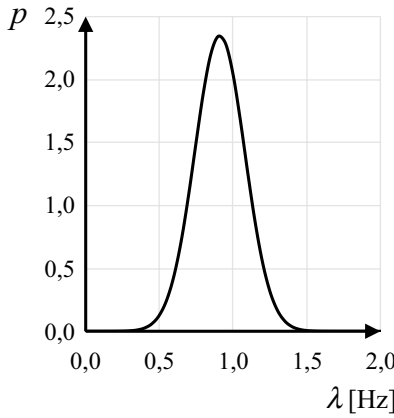

Fig. 2 Distributions of the probability density functions of a given frequency excitation by walking: a vibrations excitation along the scaffolding decks, $\mathbf{b}$ vibrations excitation in the direction perpendicular to scaffolding plane occurring between the frequency of vibrations excitation by a walking worker and the scaffolding natural vibrations. This quantity will be called the predictor of occurrence of a dangerous situation due to vibrations, induced by a walking employee. Further in this work, it will be just called the predictor and marked with the symbol $\Omega$.

\subsubsection{Examination of scaffolding response to worker's movement}

The determination of the predictor requires an analysis of the scaffolding behavior during human passage. For this purpose, the frequencies and the natural mode shapes of vibrations were determined and numerical simulations of the worker's movement on the penultimate deck, at two scaffoldings of the heights of $27.2 \mathrm{~m}$ and $55.2 \mathrm{~m}$ were carried out. All calculations were performed in Autodesk Simulation Multiphysics 2013.

The $55.2 \mathrm{~m}$ high scaffolding was modeled based on the data of a scaffoldings tested in the ORKWIZ project. The only exceptions differing the model from the real structure were in the perfect geometry adopted in analyzes and the anchor and bracing system improved under the recommendations of [59]. The scaffolding was made of Hünnebeck's BOSTA 70 frame system components. The scaffolding dimensions and boundary conditions used in the model are shown in Fig. 3. The detailed description of the principles of scaffolding modeling along with verification of the results can be found in $[60,61]$. The $27.2 \mathrm{~m}$ high scaffolding was obtained by reducing the $55.2 \mathrm{~m}$ scaffolding height.

There was another scaffolding built in the vicinity of the analyzed scaffolding at its left side. The impact of the adjacent scaffolding was modeled with use of spring supports. Adjustment of these supports stiffnesses in the range from 15 to $2000 \mathrm{kN} / \mathrm{m}$ allowed for obtaining the first natural frequency of the scaffolding at the levels from 1.0 to $3.4 \mathrm{~Hz}$. The first four mode shapes of free vibrations are in the prevailing direction along the scaffolding façade. The results of modal analysis are the frequencies of free vibrations listed in Tables 1 and 2 .

The mode shapes related to these frequencies are presented in Fig. 4 (for the lower scaffolding at exemplary stiffness of spring supports equal to $410 \mathrm{kN} / \mathrm{m}$ ) and Fig. 5 (for the higher scaffolding at $465 \mathrm{kN} / \mathrm{m}$ ). Similar mode shapes were also obtained at other values of stiffness of spring supports and resulting free vibration frequencies, which were shown in the tables above.

The simulation of human passage consisted in application of a set of forces (three components) variable in time (Fig. 1) to the nodes where the feet are placed in the following steps. Mass of the walking person was not taken into account, nor the changing distribution of mass in the walking person-scaffolding system. Because the passage on the scaffolding deck 


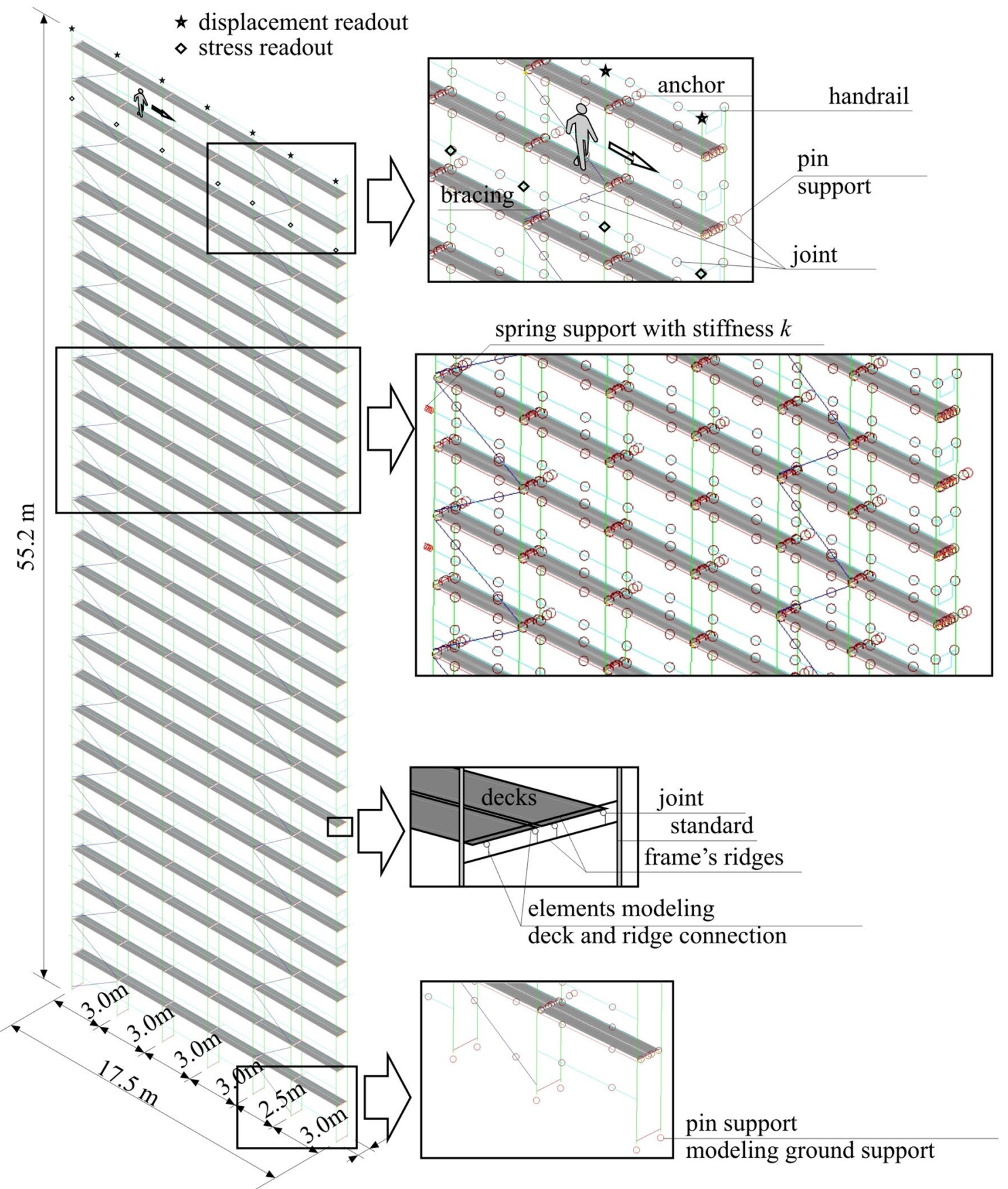

Fig. 3 Scaffolding model

Table 1 Natural frequencies of the $27.2 \mathrm{~m}$ height scaffolding

\begin{tabular}{llllllllll}
\hline $\begin{array}{l}\text { Natural fre- } \\
\text { quencies }(\mathrm{Hz})\end{array}$ & \multicolumn{2}{l}{ Stiffness of spring supports $(\mathrm{kN} / \mathrm{m})$} \\
\cline { 2 - 10 } & 15.0 & 95.0 & 155.0 & 200.0 & 230.0 & 270.0 & 310.0 & 410.0 & 2000.0 \\
\hline$f_{1}$ & 1.00 & 1.51 & 1.78 & 1.91 & 2.00 & 2.10 & 2.20 & 2.39 & 3.38 \\
$f_{2}$ & 2.54 & 2.77 & 2.92 & 3.02 & 3.08 & 3.15 & 3.22 & 3.38 & 4.33 \\
$f_{3}$ & 4.78 & 4.87 & 4.93 & 4.98 & 5.00 & 5.03 & 5.06 & 5.13 & 5.57 \\
$f_{4}$ & 6.00 & 6.05 & 6.08 & 6.10 & 6.12 & 6.13 & 6.15 & 6.18 & 6.38 \\
\hline
\end{tabular}


Table 2 Natural frequencies of the $55.2 \mathrm{~m}$ height scaffolding

\begin{tabular}{llllllllll}
\hline $\begin{array}{l}\text { Natural fre- } \\
\text { quencies }(\mathrm{Hz})\end{array}$ & \multicolumn{2}{l}{ Stiffness of spring supports $(\mathrm{kN} / \mathrm{m})$} \\
\cline { 2 - 10 } & 50.0 & 130.0 & 193.0 & 240.0 & 275.0 & 310.0 & 355.0 & 465.0 & 1100.0 \\
\hline$f_{1}$ & 0.99 & 1.49 & 1.75 & 1.91 & 2.00 & 2.10 & 2.20 & 2.40 & 3.01 \\
$f_{2}$ & 1.51 & 1.91 & 2.15 & 2.30 & 2.40 & 2.49 & 2.60 & 2.83 & 3.55 \\
$f_{3}$ & 2.55 & 2.79 & 2.95 & 3.05 & 3.12 & 3.18 & 3.26 & 3.43 & 3.99 \\
$f_{4}$ & 3.71 & 3.86 & 3.96 & 4.03 & 4.08 & 4.12 & 4.17 & 4.28 & 4.68 \\
\hline
\end{tabular}

a

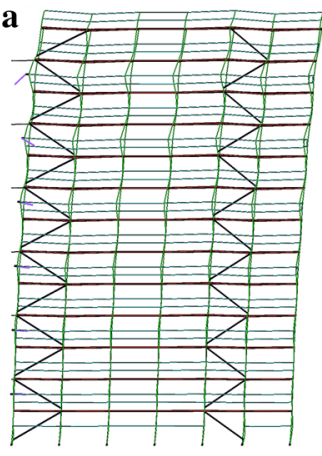

b

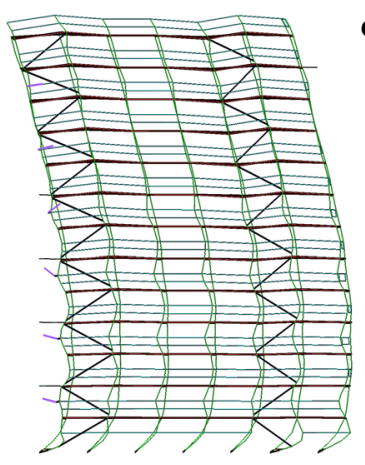

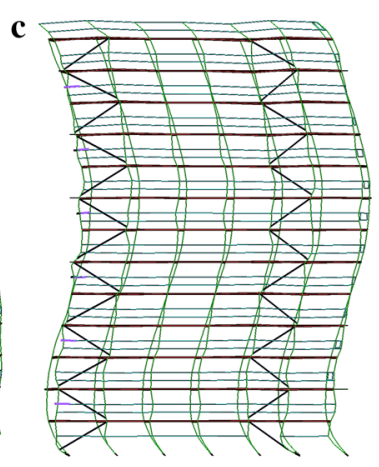

d

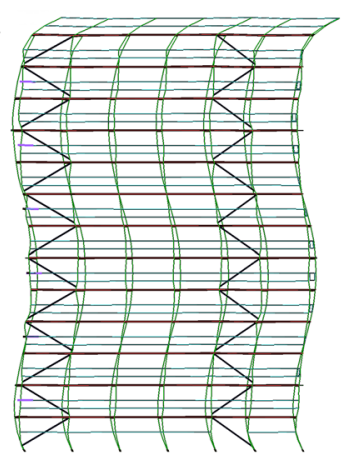

Fig. 4 Mode shapes for lower scaffolding: $\mathbf{a} f_{1}=2.39 \mathrm{~Hz}, \mathbf{b} f_{2}=3.38 \mathrm{~Hz}, \mathbf{c} f_{3}=5.13 \mathrm{~Hz}, \mathbf{d} f_{4}=6.18 \mathrm{~Hz}$
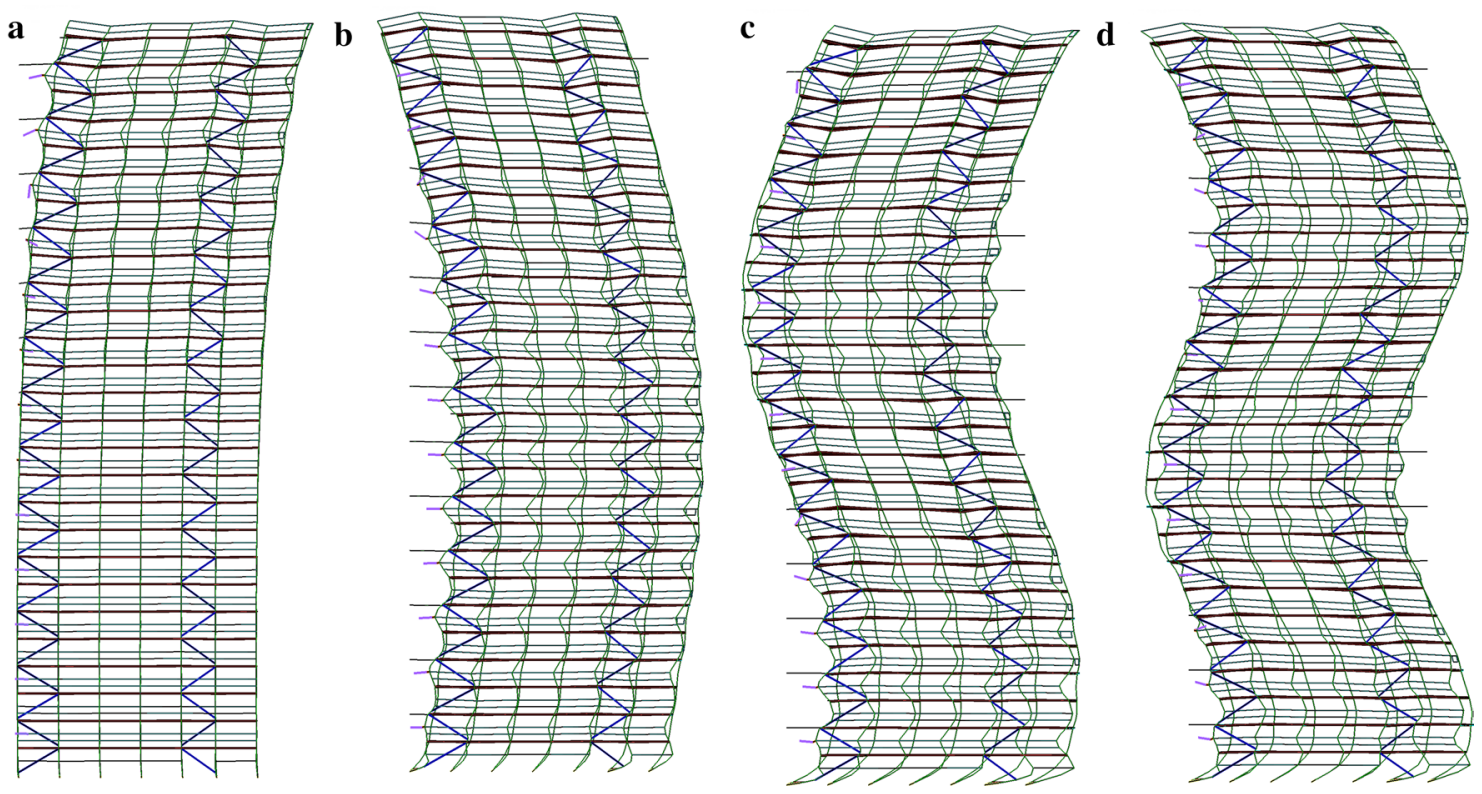

Fig. 5 Mode shapes for higher scaffolding: $\mathbf{a} f_{1}=2.40 \mathrm{~Hz}, \mathbf{b} f_{2}=2.83 \mathrm{~Hz}, \mathbf{c} f_{3}=3.43 \mathrm{~Hz}, \mathbf{d} f_{4}=4.28 \mathrm{~Hz}$

is more difficult than on the ground, in simulations lower characteristic values of walk parameters were assumed, i.e. $0.5 \mathrm{~m}$ of step length and $1.0 \mathrm{~m} / \mathrm{s}$ of movement speed. When walking with these parameters, the frequency of excitation along the scaffolding is $2 \mathrm{~Hz}$ and in the transverse direction it is $1 \mathrm{~Hz}$. The simulation of human passage on scaffolding was made using modal superposition. The model used diagonal mass matrix with no rotational dynamic degrees of freedom. The dynamic analysis consisted of 2000 steps of $0.01 \mathrm{~s}$. Damping was defined by a single critical damping fraction $\gamma$ independent of the vibration frequency.

The obtained results are time series of displacements, internal forces, and normal stresses in the elements of the structure. Based on these calculation results, Figs. 6 and 7 


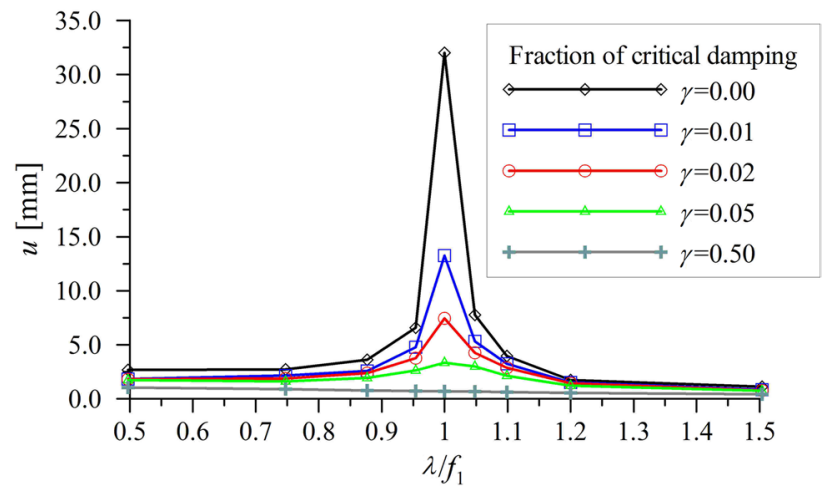

Fig. 6 Graphs of maximum displacements in relation to the critical damping fraction $\gamma$ and the ratio of the excitation frequency to the first natural frequency $\lambda / f_{1}$ for a $55.2 \mathrm{~m}$ high scaffolding

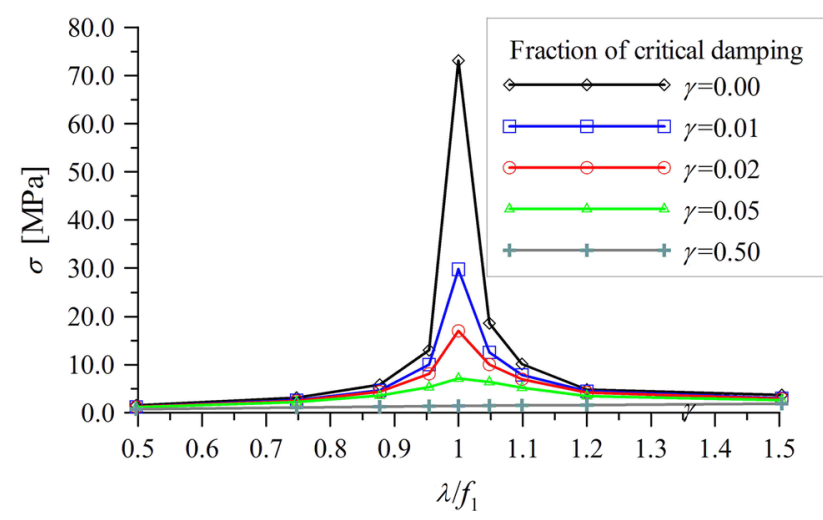

Fig. 7 Graphs of maximum normal stresses in relation to the critical damping fraction $\gamma$ and the ratio of the excitation frequency to the first natural frequency $\lambda / f_{1}$ for a $55.2 \mathrm{~m}$ high scaffolding

have been elaborated. Figure 6 presents graphs of maximum displacements at the connection points of the highest level handrails with standards (see Fig. 3-“displacement readout"). The lines in this graph are given for different values of critical damping fraction $\gamma$ and the horizontal axis represents ratios of the excitation frequency to the first natural frequency $\lambda / f_{1}$. On the other hand, Fig. 7 presents similar graph, but of maximum normal stresses in the stands at the distance of $4 \mathrm{~m}$ below the level of highest handrails (see Fig. 3- "stress readout"). Different values of the ratio $\lambda / f_{1}$ were obtained by changing the stiffness of spring supports, which causes changes in the natural frequencies. For both graphs, the maximum values from the respective sets of points in time of the human passage on scaffolding deck are presented. The shape of all graphs is similar to curves describing the dynamic factor $\beta$ depending on the frequency of excitation and damping for a system with one degree of freedom. The dynamic factor $\beta$ is described by the commonly known formula (e.g. [54]):

$$
\beta=\frac{1}{\sqrt{\left(1-\left(\frac{\lambda}{f}\right)^{2}\right)^{2}+4 \gamma^{2}\left(\frac{\lambda}{f}\right)^{2}}},
$$

where $f$ is the natural vibrations frequency, $\gamma$ is the fraction of critical damping, $\lambda$ is the excitation frequency.

This is shown in detail in Fig. 8, where the graphs of maximum displacements and maximum relative normal stresses for both scaffoldings are compiled with the graph of dynamic factor $\beta$ at the fraction of critical damping $\gamma=0.05$. Relative values were obtained by normalizing the results to the values obtained for the excitation with the ratio $\lambda / f_{1}=0.5$.

The results of the calculations do not follow exactly the curve describing the dynamic factor $\beta$. This is because the scaffolding is not a system with one degree of freedom. Just like for any other structure, vibrations excitation with frequencies close to the natural frequencies leads to resonance. Therefore, the shapes of the graphs are similar and, what is most important for this issue, in a certain range of frequencies around the resonance frequency there is an increase in displacements, internal forces and normal stresses at all the graphs. This observation was used to determine the predictor value. The methodology of obtaining the predictor is described in the next section.
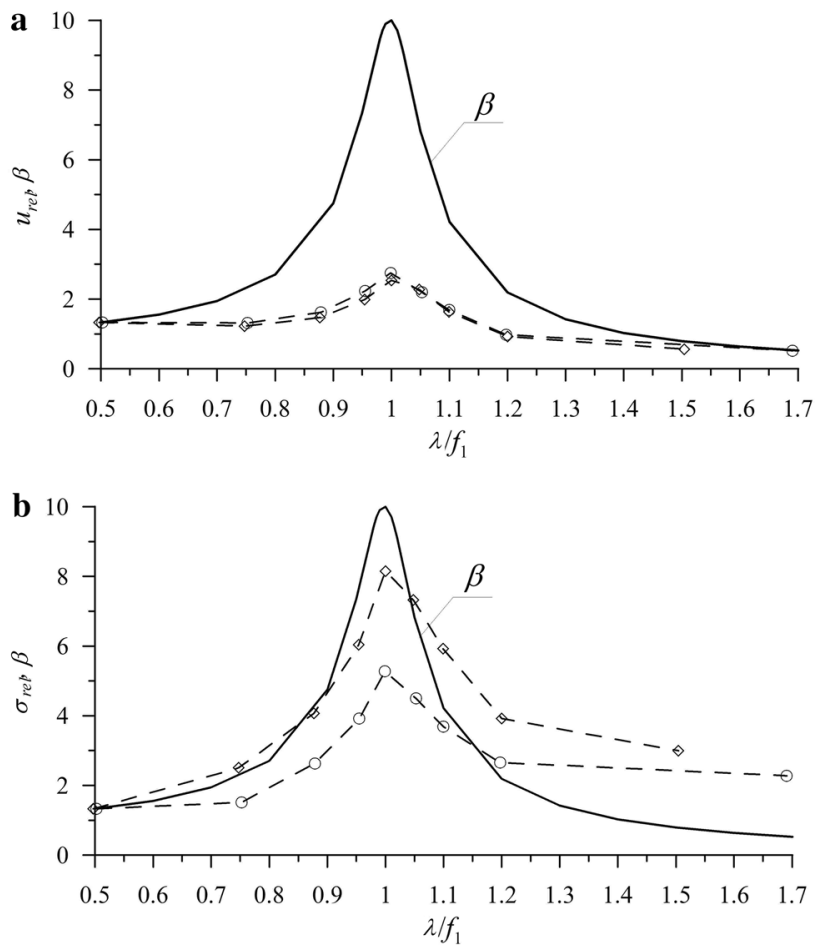

Fig. 8 Comparison of the scaffolding response to the dynamic factor at the critical damping fraction $\gamma=0.05$ : a relative displacements, $\mathbf{b}$ relative normal stresses; scaffolding with the height: circle $-27.2 \mathrm{~m}$, diamond- $55.2 \mathrm{~m}$ 


\subsubsection{Predictor of a hazardous situation due to vibrations}

The predictor value $\Omega$ is defined as the area under the plot line of probability of vibrations excitation by human movement, limited by the frequencies of excitation determined at the given value of the dynamic factor $\beta$ (Fig. 9). These frequencies were calculated on the basis of the formula (3). After its transformation, we get the equation:

$\lambda_{i}^{4}+2 f_{i}^{2}\left(2 \gamma^{2}-1\right) \lambda_{i}^{2}+f_{i}^{4}\left(1-\frac{1}{\beta^{2}}\right)=0$.

The equation has two roots, which are two frequency values limiting the range in which the excitation frequencies are dangerous to the scaffolding due to resonance. These frequencies are described by the formulas:

$\lambda_{i 1}^{2}=f_{i}^{2}\left(1-2 \gamma^{2}-\kappa\right)$,

$\lambda_{i 2}^{2}=f_{i}^{2}\left(1-2 \gamma^{2}+\kappa\right)$

where $\kappa=\sqrt{4 \gamma^{4}-4 \gamma^{2}+\frac{1}{\beta^{2}}}, f_{i}$ is the $i$ th natural frequency [Hz], at which parameters $\lambda_{1}$ and $\lambda_{2}$ are calculated.

The area bounded by the abscissa, vertical axes $\lambda=\lambda_{1}$ and $\lambda=\lambda_{2}$, and the plot of the probability density function $p(\lambda)$ of the forcing frequency occurrence during the worker's movement is a measure of the probability of adverse resonance effects occurrence. This area is shown in Fig. 9. This measure, as previously written, has been called the predictor of the occurrence of dangerous situations due to vibrations induced by a walking worker. The probability of resonance is not only affected by the first natural frequency. If the subsequent frequencies are low enough,

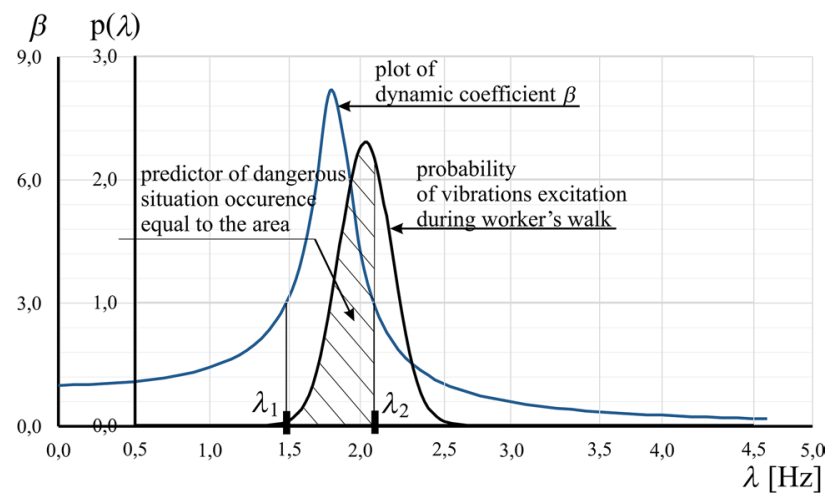

Fig. 9 Determination of the predictor of hazardous situations due to resonance they will also be important and the formula describing the predictor can be taken in the form:

$\Omega=\sum_{i=1}^{N} \alpha_{i} \Omega_{i}\left(f_{i}\right)$,

where $\Omega_{i}$ is the predictor of occurrence of resonance between excitation and $i$ th natural frequency, $\alpha_{i}$ is the weight of the importance of subsequent frequencies.

The predictor of occurrence of resonance between excitation and $i$ th natural frequency should be calculated with use of the following formulas:

- if $i$ th frequency is associated with the mode shape with dominant displacements along the scaffolding façade:

$$
\Omega_{i}\left(f_{i}\right)=\int_{\lambda_{i 1}}^{\lambda_{i 2}} p_{I}(\lambda) \mathrm{d} \lambda,
$$

- if $i$ th frequency is associated with the mode shape with dominant displacements perpendicular to the scaffolding façade:

$$
\Omega_{i}\left(f_{i}\right)=\int_{\lambda_{i 1}}^{\lambda_{i 2}} p_{\mathrm{II}}(\lambda) \mathrm{d} \lambda .
$$

The functions $p_{\mathrm{I}}(\lambda)$ and $p_{\mathrm{II}}(\lambda)$ are described with Eqs. (1) and (2).

When determining the predictor $\Omega$, only these frequencies that correspond to the mode shapes affecting large areas of scaffolding should be considered. If there is a weaker place in the scaffolding structure, then among the mode shapes there will be one with vibrations affecting only a fragment of the scaffolding. A worker moving on another part of the scaffolding will not excite scaffolding vibrations related to this mode shape.

Because the excitation frequencies by human walking are less than $3 \mathrm{~Hz}$ [54], it is enough to consider the natural frequencies not exceeding $4 \mathrm{~Hz}$ to determine the predictor $\Omega$.

The last remaining issue is to determine the number of natural frequencies that should be considered in formula (6) and the weights values $\alpha_{i}$. According to the recommendations mentioned in [54], it is proposed to include one or two natural frequencies in calculations. If two frequencies are considered, weights equal to $\alpha_{i}=0.5$ should be applied. 
Fig. 10 Values of the predictor $\Omega$ in relation to the first natural frequency $f_{1}$ at $\beta=3$ and $\gamma=0.04$ for: a the $27.2 \mathrm{~m}$ high scaffolding, b the $55.2 \mathrm{~m}$ high scaffolding

\section{a}

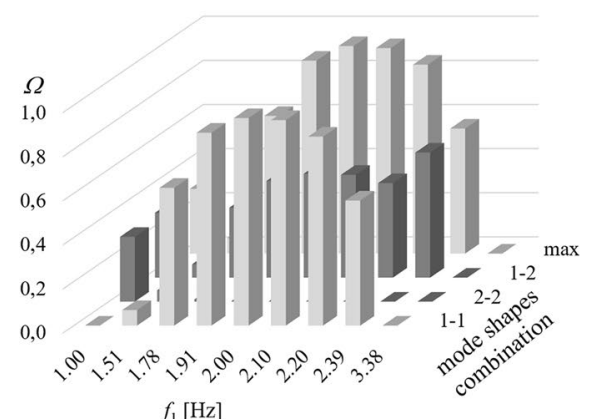

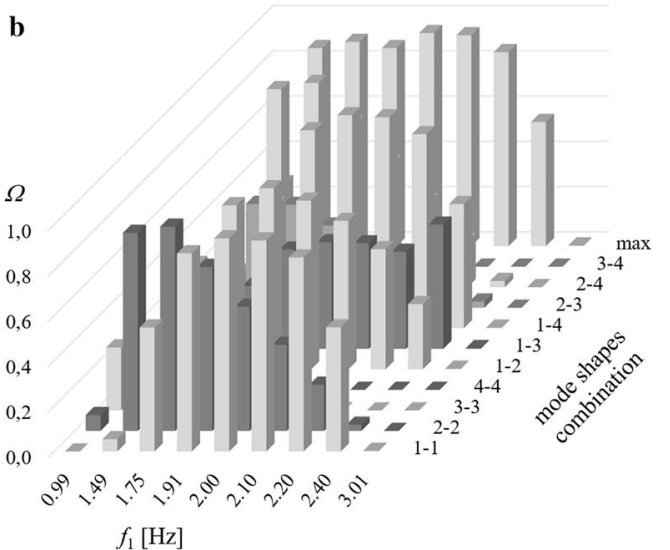

\section{Results and discussion}

\subsection{Predictor calculations for scaffoldings with perfect geometry}

For the scaffoldings described in Sect. 3.2.1, calculations of the predictors $\Omega$ were made, using the assumptions given above. For the $27.2 \mathrm{~m}$ high scaffolding, predictor values were determined for the first natural frequency (1-1), for the second natural frequency (2-2) and for both frequencies (1-2). Only two first frequencies were considered in this case, because higher frequencies exceeded the $4 \mathrm{~Hz}$ limit. For the higher scaffolding, the first four natural frequencies were considered in the calculations since all of them were below $4 \mathrm{~Hz}$ at least for some lower values of spring support stiffness. Analysis was done for single frequencies $(1-1,2-2,3-3,4-4)$ and combinations of frequency pairs $(1-2,1-3,1-4,2-3,2-4,3-4)$. If two frequencies (mode shapes) were combined, then the weights equal to $\alpha_{i}=0.5$ were used for each frequency in pair when calculating the predictor $\Omega$ value with use of (6). Figure 10 shows how the predictor values change for individual frequency combinations depending on the first natural frequency $f_{1}$, obtained at various values of stiffness of spring supports. The last row in these graphs (max) collects extreme values obtained for various frequencies (mode shapes) or their combinations. The first frequency has the greatest impact on the predictor value. The predictor values calculated for this frequency $(1-1)$ or combinations with this frequency $(1-2,1-3$ or $1-4)$ are the highest ones. Of course, when subsequent natural frequencies approach the frequency of vibration excitation, the predictor values are also significant.

The values of predictors are also affected by the value of the assumed dynamic factor $\beta$ threshold and damping. Such relationships for both scaffoldings are shown in Figs. 11 and 12. The values of the predictors in these graphs are the maximum values obtained for the analyzed combinations. At small dynamic factor $\beta$ values and small values of the critical damping fraction, the predictor values are high and decrease as these parameters increase. The figures show that at natural frequencies much lower than the excitation frequency, the predictor values in the large area of this chart are low or even equal to zero. This area is reduced when among the analyzed natural frequencies there are ones close to the excitation frequency. When the natural frequencies are higher, the predictor values approach zero value again. If any of the natural frequencies is close to the excitation frequency, then the shapes of the graphs (Figs. 11c, 12b, c) are remarkably similar to each other.

In all parts of Fig. 11 at $\beta=1$ for the analyzed range of excitation frequency the predictor $\Omega=1$ and it is independent of the level of damping. This is because the value of the coefficient $\beta=1$ means that the natural frequencies taken into account are in the range from $\lambda_{1}=0$ to $\lambda_{2}>>f_{i}$. And this means that the predictor $\Omega$ is equal to almost the entire area under the $p(\lambda)$ plot, which is equal to 1 .

If the value of the predictor is close to zero or equal to zero, then the scaffolding vibrations will not be excited during the worker's movement and thus, for this reason, the stress in the structural elements and the discomfort of users of the scaffolding will not increase. Of course, when the dynamic factor threshold level decreases, then reduction of the predictor value requires increase of the value of the critical damping fraction. Offset of the natural frequencies from the resonance frequency also reduces the predictor values down to zero.

\subsection{Predictor for real scaffolding structures}

Following [20, 48], the values of the first free vibrations frequencies of the scaffoldings are in the range from 1.0 to $4.0 \mathrm{~Hz}$. Of the 120 scaffoldings tested in the ORKWIZ project, 32 scaffoldings had the first frequency close to $2.0 \mathrm{~Hz}$. For $85 \%$ of scaffoldings, the first mode shape relates to longitudinal vibrations. The values of the critical damping 
Fig. 11 Values of the predictor $\Omega$ in relation to dynamic factor $\beta$ and fraction of critical damping $\gamma$ for the $27.2 \mathrm{~m}$ high scaffolding at: $\mathbf{a} f_{1}=1.00 \mathrm{~Hz}, \mathbf{b}$ $f_{1}=1.51 \mathrm{~Hz}, \mathbf{c} f_{1}=2.00 \mathrm{~Hz}, \mathbf{d}$ $f_{1}=2.39 \mathrm{~Hz}$

Fig. 12 Values of the predictor $\Omega$ in relation to dynamic factor $\beta$ and fraction of critical damping $\gamma$ for the $55.2 \mathrm{~m}$ high scaffolding at: $\mathbf{a} f_{1}=0.99 \mathrm{~Hz}, \mathbf{b}$ $f_{1}=1.49 \mathrm{~Hz}, \mathbf{c} f_{1}=2.00 \mathrm{~Hz}, \mathbf{d}$ $f_{1}=2.40 \mathrm{~Hz}$
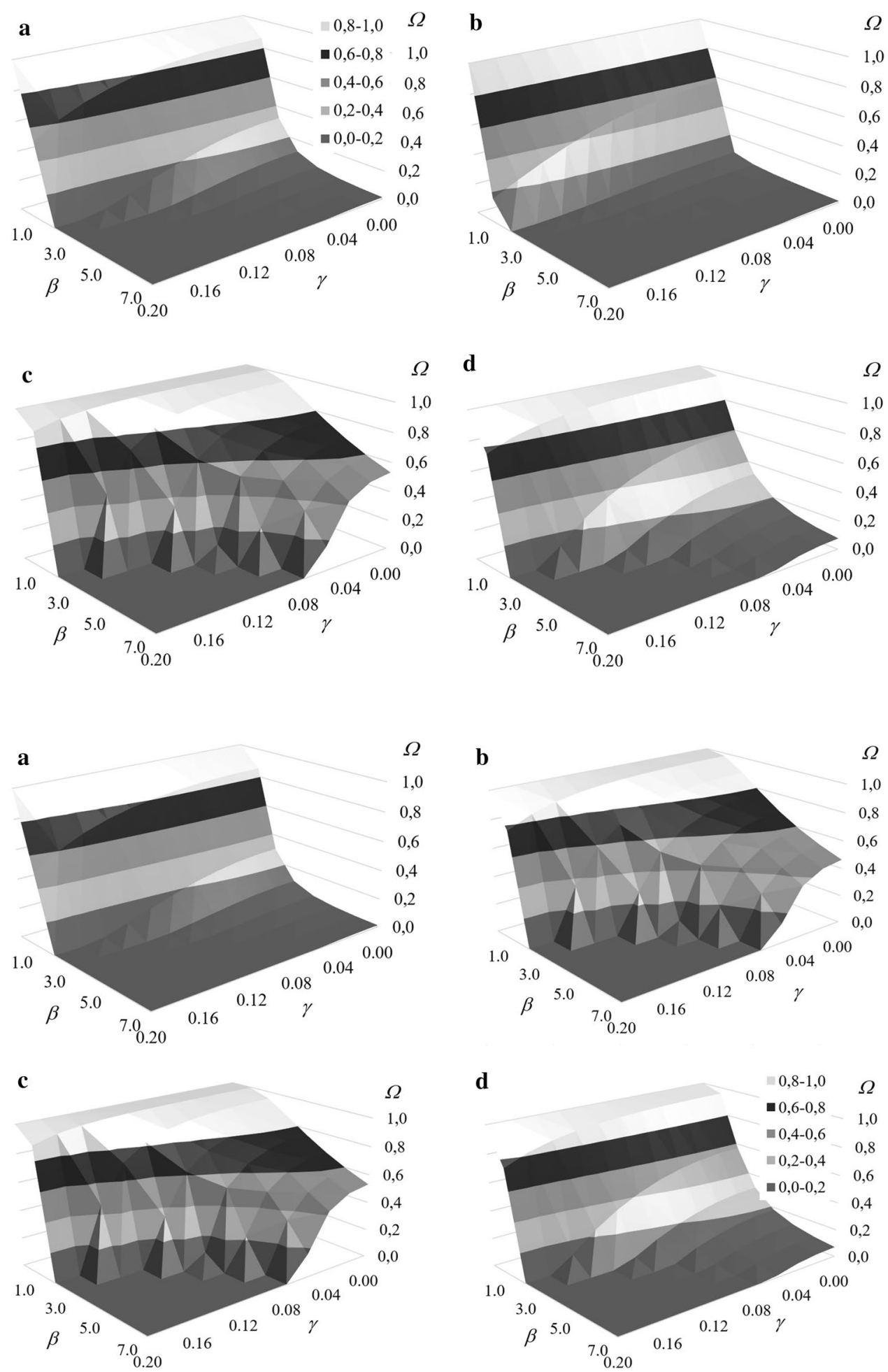

fraction vary from 0.03 to 0.065 . Scaffoldings, which are characterized by these parameters, vibrate when workers walk on them. Figure 13 shows the histograms of the predictor values for 120 scaffoldings at $\gamma=0.05$ and $\beta=3.0$. This figure presents the results for single natural frequencies and combinations of two frequencies. As it can be seen, the worst results, meaning the largest number of scaffoldings with probability of accident exceeding 0.5 is combination of mode shapes 1 and 4 . For over 50\% of the scaffoldings, the predictor of a dangerous situation due to scaffolding vibrations caused by a walking worker has been obtained with the value greater than 0.5 . This means that for $50 \%$ of 


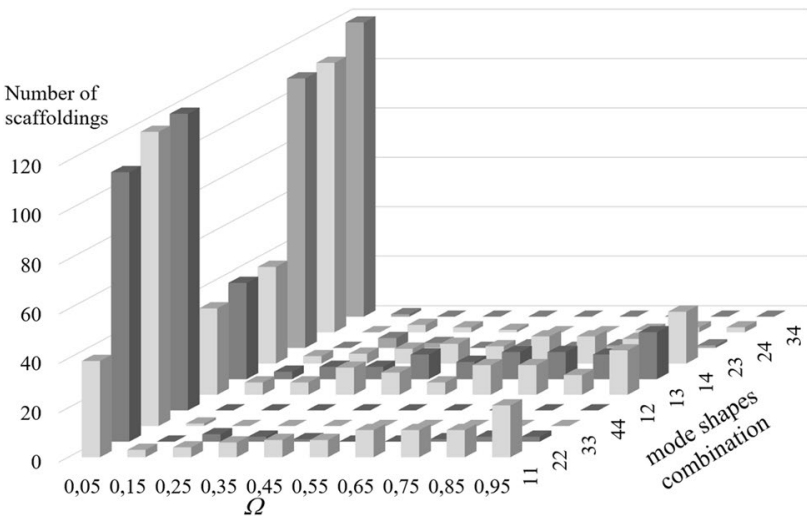

Fig. 13 Histogram of the predictor values for 120 scaffoldings at $\gamma=0.05$ and $\beta=3.0$

scaffoldings the probability of a potentially accidental situation is 0.5 . This is mainly the effect of long anchors, too small number of anchors or breaking of the anchoring in the walls during scaffolding operation.

To improve safety, the natural frequencies should be increased. In the case of longitudinal vibrations, this can be done by adding more bracing and reducing lengths of anchors. Increasing the number of anchors is also important, because it increases the frequencies of free vibrations associated with the mode shapes, both along the facade and in the perpendicular direction. For high scaffoldings, these actions are not always enough to increase the first natural frequency. In such cases, you can increase safety by increasing the level of damping. Until now, there were no measures used to increase damping of scaffoldings, but it seems that this issue should be of scientific interest in the future.

\section{Conclusions}

This paper presents a method for determining the occurrence probability of vibrations induced during worker's movement. This quantity has been called the predictor and is the measure of the scaffolding rating in terms of safety. As stated in the introduction, this is one of the factors that is included in the group of technical factors of the ORKWIZ model. The $\Omega$ predictor can be tabulated for specific natural frequencies. This allows easy assessment of the scaffolding safety in this aspect, after calculating the scaffolding's natural vibrations or after determining the free vibrations of the actual structure on the construction site based on measurements. Scaffoldings with natural frequencies around $1 \mathrm{~Hz}$ in the case of vibrations perpendicular to the scaffolding façade and $2 \mathrm{~Hz}$ in the case of vibrations along the scaffolding are likely to vibrate when workers move along the scaffolding. These vibrations are most felt at scaffoldings with lower damping.
During scaffolding design of both typical and atypical constructions, one must determine the natural frequencies and then, if the first natural frequency is less than $4.0 \mathrm{~Hz}$, perform a dynamic scaffolding analysis. The next step should be controlling the free vibrations of the scaffolding during its operation. A scaffolding during operation may change its geometry, elements may become loose and anchoring in the wall may be affected. This can cause a reduction in the frequencies of free vibrations and, consequently, an increase in the negative significance of dynamic loads. This is evidenced by the results of calculations of the predictor $\Omega$ for 120 scaffoldings, tested on construction sites. For $50 \%$ of these scaffoldings at $\beta=3.0$ the probability of a potentially accidental situation due to vibrations was obtained with the value $\Omega=0.5$.

Funding This work was supported by the National Centre for Research and Development within the Applied Research Programme (agreement No. PBS3/A2/19/2015 "Modelling of Risk Assessment of Construction Disasters, Accidents, and Dangerous Incidents at Workplaces Using Scaffoldings").

\section{Declarations}

Conflict of interest On behalf of all authors, the corresponding author states that there is no conflict of interest.

Open Access This article is licensed under a Creative Commons Attribution 4.0 International License, which permits use, sharing, adaptation, distribution and reproduction in any medium or format, as long as you give appropriate credit to the original author(s) and the source, provide a link to the Creative Commons licence, and indicate if changes were made. The images or other third party material in this article are included in the article's Creative Commons licence, unless indicated otherwise in a credit line to the material. If material is not included in the article's Creative Commons licence and your intended use is not permitted by statutory regulation or exceeds the permitted use, you will need to obtain permission directly from the copyright holder. To view a copy of this licence, visit http://creativecommons.org/licenses/by/4.0/.

\section{References}

1. Eurostat. Accidents at work by sex, age, severity, NACE Rev. 2 activity and specific physical activity [Internet]. 2019. https:// appsso.eurostat.ec.europa.eu/nui/submitViewTableAction.do. [cited 15 Jul 2019]

2. Eurostat. Employment by NACE Rev. 2 activity, age and European socio-economic group [Internet]. 2019. https://appsso.eurostat.ec. europa.eu/nui/submitViewTableAction.do. [cited 23 May 2019]

3. Błazik-Borowa E, Czarnocki K, Dąbrowski A, Hoła B, Misztela A, Obolewicz J, et al. Work safety in the construction industry. Lublin: Lublin University of Technology; 2015.

4. Whitaker SM, Graves RJ, James M, McCann P. Safety with access scaffolds: development of a prototype decision aid based on accident analysis. J Saf Res. 2003;34:249-61.

5. Jin R, Zou PXW, Piroozfar P, Wood H, Yang Y, Yan L, et al. A science mapping approach based review of construction safety 
research. Saf Sci. 2019;113:285-97. https://doi.org/10.1016/j.ssci. 2018.12.006.

6. Czarnocki K, Błazik-Borowa E, Czarnocka E, Szer J, Hoła B, Rebelo M, et al. Scaffold use risk assessment model for construction process safety. In: Fidelis E, Mike B, editors., et al., Heal people constr conf "towards better safety, heal wellbeing, life constr conf proc. Bloemfointein: Department of Built Environment Central University of Technology; 2017. p. 275-84.

7. Błazik-Borowa E, Bęc J, Robak A, Szulej J, Wielgos P. Technical factors affecting safety on a scaffolding. In: Fidelis E, Mike B, editors. Int safety, heal people constr conf "towards better safety, heal wellbeing, life constr conf proc. Bloemfointein: Department of Built Environment Central University of Technology; 2017. p. 154-63.

8. Błazik-Borowa E, Borowa A, Kawecki B, Kotowicz M, Robak A. Geodesic inventory of scaffolding geometry. Eng Struct. 2019;196:109360.

9. Jabłoński M, Szer I, Szer J. Probability of occurrence of health and safety risks on scaffolding caused by noise exposure. J Civ Eng Manag. 2018;24:437-43.

10. Pieńko M, Robak A, Błazik-Borowa E, Szer J. Safety conditions analysis of scaffolding on construction sites. World Acad Sci Eng Technol Int J Civ Environ Eng. 2018;12:72-7.

11. Szer I, Błazik-Borowa E, Szer J. The influence of environmental factors on employee comfort based on an example of location temperature. Arch Civ Eng. 2017;63:163-74. https://doi.org/10. 1515/ace-2017-0035.

12. Robak A, Pieńko M, Błazik-Borowa E, Bęc J, Szer I. Analysis of exploitation damages of the frame scaffolding. MATEC Web Conf. 2019;284:08008.

13. Research project ORKWIZ. II Konferencja Naukow-techniczna Rusztowania. Praktyczne aspekty funkcjonowania rusztowań [Internet]. 2018. http://orkwiz.pollub.pl/konferencja.pdf. [cited $20 \mathrm{Jul} 2020]$

14. Błazik-Borowa E. Loads and actions on scaffolding as engineering structures. Politech. Lub. Lublin: Lublin University of Technology; 2018

15. Rebelo M, Laranjeira P, Silveira F, Czarnocki K, Blazik-Borowa E, Czarnocka E, et al. Scaffold use risk assessment model: SURAM. In: Arezes PM, Baptista JS, Barroso MP, Carneiro P, Cordeiro P, Costa N, Melo RB, Miguel AS, editors. Occup Saf Hyg VI. CRC Press; 2018. p. 335-40. https://doi.org/10.1201/ 9781351008884-59.

16. Szer I, Szer J, Hoła B. Evaluation of climatic conditions affecting workers on scaffoldings. In: Ali MA, Platko P, editors. Adv Trends Eng Sci Technol III-Proc 3rd Int Conf Eng Sci Technol. Tatranské Matliare: CRC Press; 2015. p. 603-9.

17. Szaniawska K, Czarnocki K, Wisniewski Z, Wisniewska M. Influence of the human factor on the risk of work on scaffolding. In: Arezes PM, editor. Int Conf Appl Hum Factors Ergon AHFE 2019 Adv Saf Manag Hum Factors [Internet]. Washington D.C.: Springer; 2020. p. 58-68. https://doi.org/10.1007/ 978-3-030-20497-6_6.

18. Hoła B, Nowobilski T, Rudy J, Czarnocki K. An analysis of the influence of selected factors on the accident rate in the construction industry. Czas Tech [Internet]. 2018;6. http://www.ejournals. eu/Czasopismo-Techniczne/2018/Volume-6/art/11704/.

19. Czarnigowska A. Czego brakuje rusztowaniom-przepisy a praktyka. Inżynier Budownictwa [Internet]. 2019;3:42-9. https://www. inzynierbudownictwa.pl/drukuj/11656/.

20. Bęc J, Błazik-Borowa E, Jamińska-Gadomska P, Lipecki T. Vibrational characteristics of façade frame scaffoldings. Arch Civ Eng. 2020;66:467-84. https://doi.org/10.24425/ace.2020.134408.

21. Pinto A, Nunes IL, Ribeiro RA. Occupational risk assessment in construction industry-overview and reflection. Saf Sci. 2011;49:616-24. https://doi.org/10.1016/j.ssci.2011.01.003.
22. Sousa V, Almeida NM, Dias LA. Risk-based management of occupational safety and health in the construction industry-part 1: background knowledge. Saf Sci. 2014;66:75-86. https://doi.org/ 10.1016/j.ssci.2014.02.008.

23. Chong Hui L, Siti Halipah I, Rohaida A, Nor Azalina R, Mohd NN. Causes of fall hazards in construction site management. Int Rev Manag Mark. 2016;6:257-63.

24. Nadhim EA, Hon C, Xia B, Stewart I, Fang D. Falls from height in the construction industry: a critical review of the scientific literature. Int J Environ Res Public Health. 2016;13:638.

25. Ghodrati N, Yiu TW, Wilkinson S, Shahbazpour M. A new approach to predict safety outcomes in the construction industry. Saf Sci. 2018;109:86-94.

26. Mohammadi A, Tavakolan M, Khosravi Y. Factors influencing safety performance on construction projects: a review. Saf Sci. 2018;109:382-97.

27. Yi K-J, Langford D. Scheduling-based risk estimation and safety planning for construction projects. J Constr Eng Manag. 2006;132:626-35.

28. Jannadi OA, Almishari S. Risk assessment in construction. J Constr Eng Manag. 2003;129:492-500.

29. Hallowell M, Gambatese J. A formal model for construction safety risk management. In: Constr Build Res Conf R Inst Chart Surv. Atlanta: RICS, Georgia Tech and the contributors; 2007.

30. Sousa V, Almeida NM, Dias LA. Risk-based management of occupational safety and health in the construction industry-part 2: quantitative model. Saf Sci. 2015;74:184-94. https://doi.org/10. 1016/j.ssci.2015.01.003.

31. Alomari K, Gambatese J, Nnaji C, Tymvios N. Impact of risk factors on construction worker safety: a Delphi rating study based on field worker perspective. Arab J Sci Eng. 2020. https://doi.org/10. 1007/s13369-020-04591-7.

32. Miguel P, Martins F. Advances in safety management and human factors. In: Proceedings of the AHFE 2018 international conference on safety management and human factors. Springer; 2018.

33. Bavafa A, Mahdiyar A, Marsono AK. Identifying and assessing the critical factors for effective implementation of safety programs in construction projects. Saf Sci. 2018;106:47-56. https://doi.org/ 10.1016/j.ssci.2018.02.025.

34. Aminbakhsh S, Gunduz M, Sonmez R. Safety risk assessment using analytic hierarchy process (AHP) during planning and budgeting of construction projects. J Saf Res. 2013;46:99-105. https:// doi.org/10.1016/j.jsr.2013.05.003.

35. Raviv G, Shapira A, Fishbain B. AHP-based analysis of the risk potential of safety incidents: case study of cranes in the construction industry. Saf Sci. 2017;91:298-309. https://doi.org/10.1016/j. ssci.2016.08.027.

36. Shi S, Jiang M, Liu Y, Li R. Risk assessment on falling from height based on AHP-fuzzy. Proc Eng. 2012;45:112-8. https:// doi.org/10.1016/j.proeng.2012.08.130.

37. Ilbahar E, Karaşan A, Cebi S, Kahraman C. A novel approach to risk assessment for occupational health and safety using Pythagorean fuzzy AHP \& fuzzy inference system. Saf Sci. 2018;103:124-36.

38. Rubio-Romero JC, Rubio Gámez MC, Carrillo-Castrillo JA. Analysis of the safety conditions of scaffolding on construction sites. Saf Sci. 2013;55:160-4. https://doi.org/10.1016/j.ssci.2013. 01.006 .

39. Błazik-Borowa E, Szer J. The analysis of the stages of scaffolding "life" with regard to the decrease in the hazard at building works. Arch Civ Mech Eng. 2015;15:516-24.

40. Nuraffefa H, Hanizam A. Safety scaffolding in the construction site. J Teknol (Sciences Eng). 2015;75:26-31. www.jurnaltekn ologi.utm.my.

41. Hoła A, Hoła B, Szóstak M. Analysis of the causes and consequences of falls from scaffolding using the Polish construction 
industry as an example. In: IOP Conf. Ser. Mater. Sci. Eng. IOP Publishing; 2017. p. 012050. https://doi.org/10.1088/1757-899X/ 251/1/012050.

42. Abas NH, Noridan MR, Rahmat MH, Abas NA, Ibrahim NQ. Causes of accidents involving scaffolding at construction sites causes of accidents involving scaffolding at construction sites. J Technol Manag Bus. 2020;7:75-86.

43. Harms-Ringdahl L. Safety analysis. Principles and practice in occupational safety. London: Taylor \& Francis; 2005.

44. Błazik-Borowa E, Szer J. Basic elements of the risk assessment model for the occurrence of dangerous events on scaffoldings. Przegląd Bud. 2016;10:24-9.

45. Bird FE, Germain GL. Practical loss control leadership. Loganville: International Loss Control Institute; 1986.

46. Armstrong TJ, Buckle P, Fine JF, Hagberg M, Jonsson B, Kilbom A, et al. A conceptual model for work-related neck and upperlimb musculoskeletal disorders. Scand J Work Environ Health. 1993;19:73-84.

47. Jebelli H, Ahn CR, Stentz TL. Fall risk analysis of construction workers using inertial measurement units: validating the usefulness of the postural stability metrics in construction. Saf Sci. 2016;84:161-70. https://doi.org/10.1016/j.ssci.2015.12.012.

48. Bęc J, Błazik-Borowa E. Dynamic properties of façade frame scaffoldings. MATEC Web Conf. 2019;285:00001. https://doi.org/10. 1051/matecconf/201928500001.

49. Cyniak P, Szer I, Szer J, Lipecki T, Błazik-Borowa E. Impact of dynamic load on scaffold construction effort. J Civ Eng Environ Archit. 2017;64:487-97.

50. Matsumoto Y, Sato S, Nishioka T, Shiojiri H. A study on design of pedestrian over-bridges. Trans JSCE. 1972;4:50-1.

51. Matsumoto Y, Nishioka T, Shiojiri H, Matsuzaki K. Dynamic design of footbridges. Zurich: IABSE; 1978. p. 1-15.

52. Wiss JF, Wiss J, Parmelee RA. Human perception of transient vibrations. J Struct Div. 1974;100:773-87.
53. Andriacchi TP, Ogle JA, Galante JO. Walking speed as a basis for normal and abnormal gait measurements. J Biomech. 1977;10:261-8.

54. Bachmann H, Ammann WJ, Eisenmann J, Floegl I, Hirsch GH, Klein GK, et al. Vibration problems in structures: practical guidelines. Basel: Birkhauser Verlag; 1995.

55. Racic V, Pavic A, Brownjohn JMW. Experimental identification and analytical modelling of human walking forces: literature review. J Sound Vib. 2009;326:1-49.

56. Racic V, Brownjohn JMW. Mathematical modelling of random narrow band lateral excitation of footbridges due to pedestrians walking. Comput Struct. 2012;90-91:116-30. https://doi.org/10. 1016/j.compstruc.2011.10.002.

57. Kala J, Salajka V, Hradil P. Dynamic action induced by walking pedestrian. Int J Civ Environ Eng. 2012;6:766-9.

58. Wheeler E. Prediction and control of pedestrian induced vibration in footbridges. J Struct Div ASCE. 1982;108:2045-65.

59. EN 12810-1. Façade scaffolds made of prefabricated components. Part 1: product specifications. Brussels: European Committee for Standardization; 2010.

60. Jaminska-Gadomska P, Bęc J, Lipecki T, Robak A. Verification of the façade scaffolding computer model. Arch Civ Eng. 2018;64:42-53.

61. Cyniak P, Błazik-Borowa E, Szer J, Lipecki T, Szer I. The choice of boundary conditions and mesh for scaffolding FEM model on the basis of natural vibrations measurements. In: AIP Conf. Proc. AIP Publishing LLC; 2018. p. 150002. https://doi.org/10.1063/1. 5019155.

Publisher's Note Springer Nature remains neutral with regard to jurisdictional claims in published maps and institutional affiliations. 